\title{
Aortopulmonary fistula: role of computed tomography
}

\author{
SAM HAMPSON, JOHN PEPPER \\ From the Cardiothoracic Unit, St George's Hospital, London
}

Aortopulmonary fistula is an uncommon condition. It may occur as a result of intrathoracic pathology or as a sequel to surgery on the thoracic aorta. Emergency surgical treatment of such fistulas gives poor results and the early recognition of the condition may be life saving. We report a case and discuss the role of computed tomography in establishing the diagnosis.

\section{Case report}

A 67 year old man presented with a two month history of haemoptysis-10-20 ml of fresh blood about once a week. Eight years earlier he had undergone elective resection of a saccular aneurysm of the descending thoracic aorta of unknown aetiology. The aneurysm only had been excised and a Dacron onlay patch had been inserted. He had made an uneventful recovery and remained well until October 1985. He gave up smoking at the time of that operation. Physical examination showed a well healed thoracotomy wound but nothing else of note. Routine haematological and biochemical investigations showed no abnormality. A lateral chest radiograph showed mild dilatation of the descending aorta. Bronchoscopy revealed some fresh blood in the left lower lobe posterior basal segmental bronchus. Cytological examination of sputum gave normal results. Computed tomography was performed, $50 \mathrm{ml} \mathrm{N}$. ovam 300 being used as enhancement. This showed an aneur, $m$ of the mid third of the descending aorta (fig $1 a$ ) adjacen , a large airway (fig $1 b$ ). An aortogram confirmed the presince of a small aneurysm at this site but did not show a fistula.

In view of the continuing haemoptysis we proceeded to an exploratory left thoracotomy on 11 December 1985. Mobilisation of the left lower lobe revealed an area of the posterior basal segment that was densely adherent to a false aneurysm arising from the edge of the original Dacron patch. The lower lobe was separated from the aorta at this point and aorto-aortic bypass established with a $9 \mathrm{~mm}$ heparinised Gott shunt. The false aneurysm, Dacron patch, and fistula were excised (fig 2), together with a complete circumference of aorta. The repair was performed with an interposition graft of low porosity Meadox Dacron. A pleural flap was raised to separate the graft from the lower lobe. A small amount of the posterior basal segment was resected with the false aneurysm and the remaining lung repaired with a stapler. The patient made a straightforward recovery and was well and active on review eight months later.

Histological examination of the aorta showed severe ath-

Address for reprint requests: Mr John Pepper FRCS, Cardiothoracic Unit, St George's Hospital, London SW170QT.

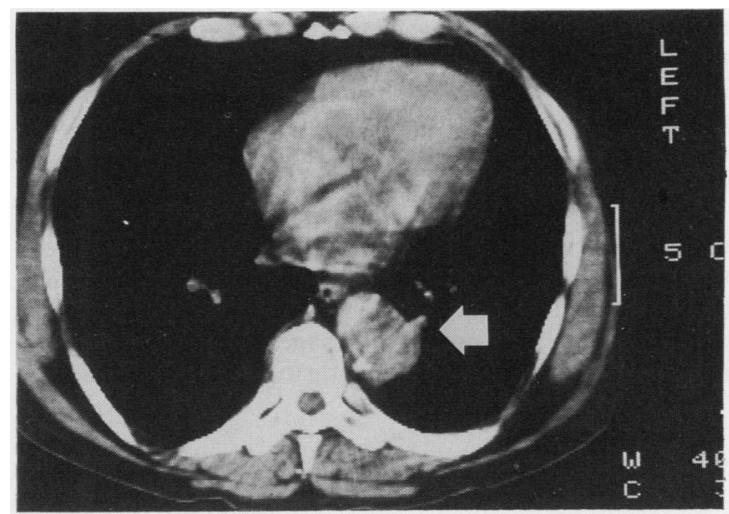

(a)

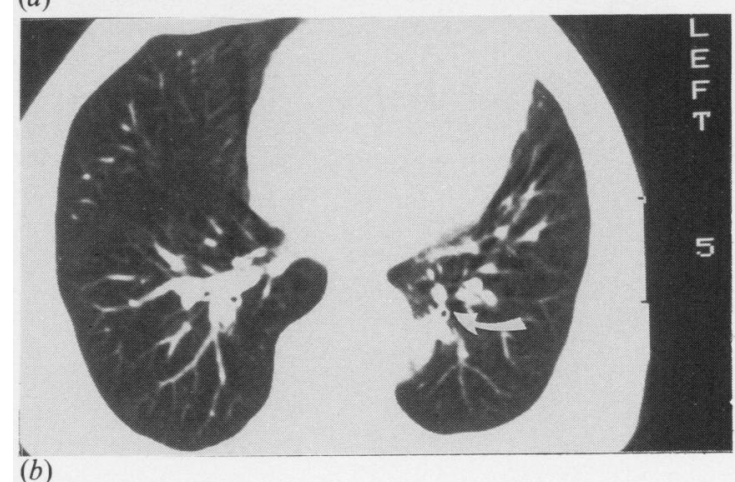

Fig 1 (a) Computed tomography scan of the thorax, which shows a small false aneurysm on the descending aorta. (b) Pulmonary cut showing the proximity of the aneurysm to the bronchus.

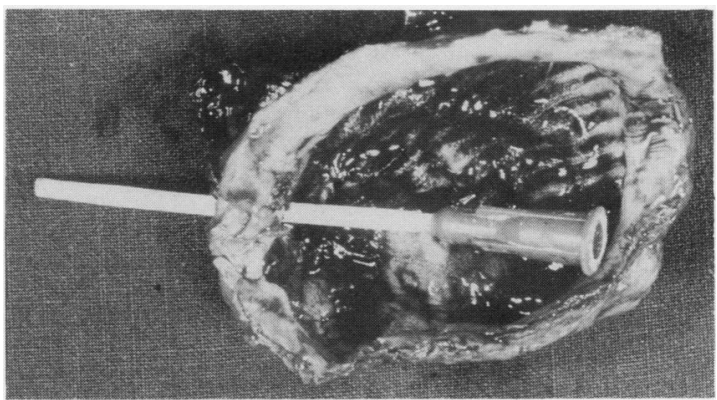

Fig 2 Excised Dacron patch and aortic wall to show the site of the fistula at the margin of original patch (indicated by cannula). 
eroma with calcification, fibrosis, and loss of the media. There was no appreciable inflammation. The small amount of lung included in the specimen contained haemosiderin and was collapsed.

\section{Discussion}

Cases of aortopulmonary fistula are reported as late complications of surgery for persistent ductus arteriosus, ${ }^{1}$ coarctation (including that of the first reported fistula), and resection of true or false aneurysm. ${ }^{2}$ Intermittent haemoptysis is the commonest presenting symptom $(70 \%$ in a collective series $\left.{ }^{3}\right)$. Delay in diagnosis may result in acute presentation with catastrophic haemorrhage. ${ }^{4}$ The fistulas may, however, be asymptomatic and pain is an unusual feature. ${ }^{4}$

Conclusive diagnosis of the condition preoperatively is difficult. Aneurysmal dilatation is often visible on a plain radiograph and in some cases a pulmonary infiltrate has been described. Da Valle 4 has warned that bronchoscopy may precipitate serious haemorrhage, but it is difficult to justify the exclusion of this investigation. Most authors are agreed that aortography, as in this case, contributes little the diagnosis, but it seems to have been universally use Computed tomography has been used in more recen cases. $^{14}$ Scans may show a mass in the lung parenchymo contiguous with the aorta but no true continuity has yef been demonstrated by contrast enhancement. In this patie the small pouch seen on the lateral wall of the ascendin aorta was in close proximity to the bronchus and therefor in the context of the history highly suggestive of a fistula.

\section{References}

1 Wood AE, Stevenson HM, Cleland J. Aortobronchial fistula: late complication of division of the persistent ductus arteriosus Ann Thorac Surg 1984;38:402-5.

2 Graeber G, Farrell B, Neville J. Successful diagnosis and managiot ment of fistulas between the aorta and the tracheobronchif tree. Ann Thorac Surg 1980;29:555-61.

3 Bryant LR, Bowlin J, Malette W. Thoracic aneurysms with aortico-bronchial fistula. Ann Surg 1968;168:79-84.

4 Da Valle MJ, Kreiger KH, Spencer FC. Aorto-pulmonary fistula in a post-coarctation mycotic aneurysm. Surgery 1985;97:93 